\title{
High Tibial Osteotomy versus Unicompartmental Knee Arthroplasty for Compartmental Knee Osteoarthritis: A Systematic Review and Meta-Analysis
}

Ishith Seth ( $\square$ ishithseth1@gmail.com)

Bendigo Health https://orcid.org/0000-0001-5444-8925

Nimish Seth

Alfred Health

Gabriella Bulloch

The University of Melbourne Melbourne Medical School

Damien Gibson

Illawarra Shoalhaven Local Health District

Kirk Lower

Illawarra Shoalhaven Local Health District

Aaron Rodwell

Illawarra Shoalhaven Local Health District

Warwick Bruce

Concord Hospital: Concord Repatriation General Hospital

\section{Research Article}

Keywords: High tibial osteotomy, Unicompartmental knee arthroplasty, Compartmental knee osteoarthritis, Meta-analysis

Posted Date: December 15th, 2021

DOI: https://doi.org/10.21203/rs.3.rs-934685/v1

License: @ (1) This work is licensed under a Creative Commons Attribution 4.0 International License. Read Full License

Version of Record: A version of this preprint was published at Indian Journal of Orthopaedics on March 21st, 2022. See the published version at https://doi.org/10.1007/s43465-022-00620-9. 


\section{Abstract}

Purpose High tibial osteotomy (HTO) and unicompartmental knee arthroplasty (UKA) are commonly performed procedures for the treatment of compartmental knee osteoarthritis. However, the optimal procedure remains controversial. Therefore, we conducted this systematic review and meta-analysis to compare the functional outcomes, complications, and revision between the two techniques.

Methods We searched electronic databases for relevant studies comparing HTO versus UKA for unicompartmental knee osteoarthritis. Continuous data as visual analogue scale (VAS), range of motion, and free walking speed were pooled as mean differences (MDs). Dichotomous data as functional knee outcomes, complications, and revision were pooled as odds ratios (ORs), with $95 \%$ confidence interval (Cl), using R software for windows.

Results Twenty-five studies involving 8185 patients were included. Meta-analysis showed that HTO was associated with higher risk of complications ( $\mathrm{OR}=2.47,95 \% \mathrm{Cl}[1.52,4.04])$, poor functional results (excellent/good) (OR= 0.32, 95\% $\mathrm{Cl}[0.21,0.49])$, and larger range of motion ( $\mathrm{MD}=7.05,95 \% \mathrm{Cl}[2.41,11.68])$ compared to UKA. No significant differences were found between the compared groups in terms of VAS $(M D=0.14,95 \% \mathrm{Cl}[-0.08,0.36])$, revision $(\mathrm{OR}=1.30,95 \% \mathrm{Cl}[0.65,2.60])$, and free walking speed $(\mathrm{MD}=-0.05,95 \% \mathrm{Cl}[-0.11,0.00])$.

Conclusion This study showed that UKA achieved fewer complications, better functional outcomes, and less range of motion compared to HTO. No significant differences were detected between HTO and UKA in terms of VAS and revision rate.

\section{Introduction}

Knee osteoarthritis is a widespread source of knee pain that causes health and financial burdens ${ }^{1}$. Despite multifactorial causes, mechanical axis deviation of the knee often causes compartmental knee osteoarthritis ${ }^{2}$. Thus, unloading the diseased compartment might relieve the deterioration of that compartment. The initial management of knee osteoarthritis includes non-operative treatment such as patient education, weight reduction, physical therapy, and pain relieving medications ${ }^{3}$. In addition, knee braces are other non-surgical options that may alter the alignment of the lower extremity ${ }^{3}$. If non-operative treatments fail, surgical treatment may be indicated that consists of high tibial osteotomy (HTO) or unicompartmental knee arthroplasty (UKA).

High tibial osteotomy is a known procedure for the treatment of patients with medial compartment knee osteoarthritis due to mechanical axis deviation ${ }^{4}$. Several methods have been developed to treat this condition, such as opening wedge (OW), closing wedge (CW), dome, and "en chevron" osteotomies; while, the most frequently used methods are medial (opening) and lateral (closing) wedge osteotomies ${ }^{5}$. It is reported that HTO is the first surgical choice for active young patients with a preserved joint stability and single compartmental knee osteoarthritis ${ }^{6}$. Although overall HTO outcomes demonstrate the efficacy of procedure ${ }^{7}$, there is still debate regarding osteotomies.

Growing evidence has shown an interest in UKA that achieves excellent outcomes with a low risk of complications in single compartmental osteoarthritis ${ }^{8}$. UKA is used for less active elderly patients with a preserved range of motion, absence of ligament instability, and compartmental knee osteoarthritis ${ }^{9}$. Nowadays, these indications have become less defined, especially in patients more than 50 years old.

Advances in surgical procedures, along with similar indications for both HTO and UKA, make the decision-making challenging. Previous studies have shown that both HTO and UKA are established solutions for compartmental knee osteoarthritis 6,10 ; however, the optimal intervention remains controversial. In the literature, there is a lack of evidence concerning the role of HTO compared to UKA for compartmental knee osteoarthritis ${ }^{11}$. Therefore, an updated systematic review and meta-analysis of clinical trials and comparative study was conducted to assess the role of HTO versus UKA for compartmental knee osteoarthritis. The current study aimed to compare the functional outcomes, complications, and revision between the two surgical techniques.

\section{Materials And Methods}

All steps of this study were conducted in accordance with the Cochrane handbook of systematic reviews of interventions in addition to Preferred Reporting Items for Systematic Reviews and Meta-Analysis (PRISMA) statement guidelines ${ }^{12}$. The protocol of this meta-analysis was published online at the International Prospective Register of Systematic Reviews (PROSPERO) under registration number (CRD42021243076).

\subsection{Literature search strategy}

We searched Medline (via PubMed), Embase, the Cochrane Library, Clinicaltrial.gov, google scholar, up to March 2021, for randomized clinical trials (RCTs) and comparative studies comparing HTO to UKA. We used the possible combinations of the keywords: "knee 
osteoarthritis", "knee arthritis", "degenerative knee", "unicompartmental knee arthroplasty", "unicondylar knee arthroplasty", "partial knee arthroplasty", "high tibial osteotomy", and osteotomies, including variant spellings and endings. Additionally, the reference lists of identified articles were checked manually.

\subsection{Eligibility criteria:}

We included RCTs and comparative studies that compared HTO with UKA for the treatment of patients with compartmental knee osteoarthritis. The included outcomes were complications (infection, leg length discrepancy, deep vein thrombosis, and pain), functional outcomes (patients have excellent/good results), visual analogue scale (VAS), revision, range of motion, and free walking speed (velocity). We excluded animal models, reviews, case reports, case series, non-English articles, and duplicate references.

\subsection{Study selection}

First, title/abstract screening for eligibility for the current study was conducted. Second, full-text screening was conducted. Each step was performed by three independent reviewers and disagreements were resolved upon consensus.

\subsection{Data Extraction}

Requisite data were extracted by three independent authors into a data extraction form. The extracted data included the following items: a) baseline characteristics of enrolled patients, b) general characteristics of study design, c) included outcomes. In case of missing the mean or standard deviation (SD), we calculated them from the equations provided in the Cochrane handbook of systematic reviews of interventions ${ }^{13}$.

\subsection{Risk of bias assessment and quality assessment}

We used Cochrane collaboration's tool for assessing the risk of bias of included RCTs ${ }^{12}$. Risk of bias assessment included: 1) sequence generation, 2) allocation sequence concealment, 3) blinding of participants and personnel, 4) blinding of outcome assessment, 5) incomplete outcome data, 6) selective outcome reporting and 7) other potential sources of bias; the authors' judgment is categorized as 'Low risk', 'High risk' or 'Unclear risk' of bias. To assess the risk of bias across included studies, we compared the reported outcomes between all studies to exclude selective reporting of outcomes. Newcastle Ottawa scale (NOS) was used to assess the quality of observational studies and each included study was assessed based on reporting of three essential domains: a) selection of the study subjects, b) comparability of groups on demographic characteristics and important potential confounders, and c) ascertainment of the included outcome (exposure/treatment) ${ }^{14}$.

\subsection{Data Synthesis}

Continuous data were pooled as mean difference (MD). Dichotomous data were pooled as odds ratio (OR), with a $95 \%$ confidence interval (Cl). We used R software (meta-package 4.9-0) for windows during data synthesis. Heterogeneity was assessed by visual inspection of the forest plots and measured by Q statistic and $I^{2}$ statistic. Significant statistical heterogeneity was indicated by Q statistic P-value less than 0.1 or by $I^{2}$ more than $50 \%$. In case of significant heterogeneity, we conducted a random effect model. Otherwise, the fixed effect model was used. Sensitivity analysis was used to resolve the heterogeneity. The funnel plot method was used to assess publication bias for outcomes with more than 10 included studies.

\section{Results}

\subsection{Search strategy results}

Our literature search yielded 2392 unique records. After title/abstract screening, 45 were retrieved and screened for eligibility. Finally, 25 studies were included in the meta-analysis. The flow of the study selection process is shown in the PRISMA flow diagram, Fig. 1.

\subsection{Characteristic of included studies}

Twenty-five studies involving 8185 patients were included. Of them, 11 studies were RCTs and 14 were observational comparative studies. A total of 1996 patients had HTO, and 6189 patients had UKA. The follow-up period ranged from 12 to 793.6 months. The age ranged from 30 to 84 years old. All articles were published in English from 1982 to 2020. A summary of the design and baseline characteristics of enrolled patients is presented in Table 1. The risk of bias and quality assessment of included studies with the references were reported in Appendix Tables 1 and 2 .

\subsection{Outcomes}

Page 3/15 


\section{Complications}

Eleven studies reported on complications (infection, leg length discrepancy, deep vein thrombosis, and pain). The effect estimate showed that $\mathrm{HTO}$ was associated with more risk of complications than UKA $(\mathrm{OR}=2.47,95 \% \mathrm{Cl}[1.52,4.04])$. No significant heterogeneity was found $\left(I^{2}=0 \%, P=0.52\right)$, Fig. 2 .

\section{Functional outcomes (excellent/good results)}

Ten studies reported on the number of patients having excellent/good results regarding the functional outcomes. The effect estimate showed that HTO was associated with poorer functional results compared to UKA (OR $=0.32,95 \% \mathrm{Cl}[0.21,0.49])$. Moderate evidence of heterogeneity was noted $\left(I^{2}=45 \%, P=0.007\right)$, Fig. 3 .

\section{Visual Analogue Scale (VAS)}

Six studies reported on VAS. The effect estimate showed no significant difference between the compared groups $(\mathrm{MD}=0.14,95 \% \mathrm{Cl}[-0.08$, $0.36])$. There was moderate evidence of heterogeneity $\left(I^{2}=50 \%, P=0.07\right)$, Appendix Fig. 1.

\section{Survival and revision}

Survival was defined as the time to a UKA revision, second operation, or an operation failure. Fourteen studies reported on revision. The total effect size was comparable between HTO and UKA $(\mathrm{OR}=1.30,95 \% \mathrm{Cl}[0.65,2.60])$. Significant heterogeneity was reported $\left(I^{2}=67 \%, P<\right.$ 0.01), Fig. 4.

\section{Range of motion}

Seven studies reported on a range of motion. The total effect size showed that HTO was associated with a larger range of motion than UKA $(\mathrm{MD}=7.05,95 \% \mathrm{Cl}[2.41,11.68])$. Significant heterogeneity was observed $\left(I^{2}=93 \%, P<0.01\right)$, Appendix Fig. 2.

\section{Free walking speed (velocity)}

Four studies reported on free walking speed (velocity), and no significant difference was showed between the compared groups $(M D=-0.05$, $95 \% \mathrm{Cl}[-0.11,0.00])$. There was no significant heterogeneity $\left(I^{2}=0 \%, P=0.52\right)$, Appendix Fig. 3 .

\section{Publication bias}

The funnel plot showed no evidence of publication bias regarding postoperative complications and revision, Appendix Figs. 4 and 5 .

\section{Discussion}

The present study compared HTO to UKA for the treatment of compartmental knee osteoarthritis. This meta-analysis of 25 studies showed that UKA achieved fewer complications, better functional outcomes (excellent/good), and reduced knee range of motion compared to HTO. No significant differences were detected between HTO and UKA in terms of visual analogue scale, revision rate, and free walking speed.

Conventionally, UKA has been used for patients over 60 years, less than $82 \mathrm{~kg}$, single compartment osteoarthritis, less than 15-degree angular deformity, and more than 90-degree range of motion ${ }^{9,15}$. UKA is contraindicated in active patients with inflammatory arthritis and less than 60 years old. However, some studies showed that UKA provided promising outcomes in younger and obese patients ${ }^{16,17}$. A retrospective series of 41 patients showed that UKA achieved a $92 \%$ survival rate at 11 years in patients ranged from 35 to 60 years old 18 . Another study including 62 patients, with 11.2 years follow-up, reported that UKA was associated with favourable outcomes and a $94 \%$ survival rate at 12 years in patients aged 60 years or younger ${ }^{19}$. Advances in the surgical procedures and implant designs, besides increased experience with the technique, have extended the surgical indications for UKA.

Both HTO and UKA share similar indications, such as patients aged 55 to 65 years, patients without obesity, patients with moderate activity, mild varus malalignment, joint stability, good range of motion, and moderate single compartmental osteoarthritis. The selection of suitable patients, accurate osteotomy types, and specific surgical techniques are important in the success of HTO ${ }^{20}$. HTO is used for young patients less than 60 years, normal weight, active patients with radiographic single-compartment osteoarthritis, stable/unstable joint, range of motion with flexion more than 120 degrees, and localized pain to the tibiofemoral joint line ${ }^{21}$. A comparative study by Trieb et al. showed a higher failure rate in the HTO group in $\geq 65$ years patients versus younger patients ${ }^{22}$. Furthermore, a prospective study including 132 
patients demonstrated that a preoperative BMI of more than $27.5 \mathrm{~kg} / \mathrm{m} 2$ was a risk factor for early failure of HTO ${ }^{4}$. Another investigation utilized a Markov model to simulate theoretical groups of patients 40,50, 60, and 70 years of age undertaking primary HTO or UKA. The results demonstrated higher revision risks at follow-up durations of 5 and 10 years in the HTO compared to the UKA group for patients $\geq 50$ years $^{23}$. A large retrospective review in the USA showed that HTO was performed more commonly in patients aged 40 to 44 years and UKA was more common in patients aged 60 to 64 years ${ }^{24}$. Selecting the correct patient is the key to success. In the present meta-analysis, the included patients' ages ranged from 30 to 84 years, which might explain why the revision rate did not differ significantly between the HTO and UKA groups.

Several techniques of HTO have been developed including opening wedge, closing wedge, dome, and "en chevron" osteotomies. Opening wedge and closing wedge are the most frequently used techniques. No differences in most of the clinical outcomes were found except the operation time ${ }^{25}$. Currently, HTO seems common again; however, there were more post-surgical complications in the HTO group compared to the UKA group in the current meta-analysis. These findings accord with previous meta-analyses ${ }^{26,27}$. The postoperative complications included the rate of infection, venous thrombosis, cortical fracture, and peroneal nerve injury. A systematic review of $12 \mathrm{HTO}$ studies showed that HTO had a complication rate up to $47 \%$ postoperatively ${ }^{28}$. The significantly higher proportion of complications after HTO may be due to surgical techniques, long-standing cast immobilization, late limb load, and inadequate fixation following HTO operation.

Regarding the knee functional outcomes, the current meta-analysis showed that the rate of excellent/good outcomes was significantly higher in the UKA group versus the HTO group, while the range of motion was higher in the HTO group versus the UKA group. However, there were no significant differences between the compared groups regarding the visual pain scale. The differences in functional outcomes and range of motion results indicate that further factors might impact functional results. Osteotomy targets transferring the mechanical axis from the abnormal position to the normal area ${ }^{29}$, which leads to improved pain and better gait, delaying the progression of osteoarthritis 20 . Nevertheless, the degenerative compartment persists. Formerly, patients undergoing HTO were placed in a plaster cast from the groin to the ankle for six weeks, and the osteotomy took several months to heal postoperatively. Compared to UKA, a resurfacing technique, in which the degenerative compartment is replaced while the normal compartments are preserved. Some studies reported on the use of modern techniques such as TomoFix plate in the HTO group compared to UKA. Koh et al. enrolled patients with OWHTO performed using TomoFix plate vs UKA. The study reported that patient satisfaction was higher in the UKA group than the HTO group in active patients ${ }^{30}$. Kim et al. used TomoFix plate in OWHTO vs UKA and reported that HTO and UKA had similar pain and functional outcomes at 12 and 24 months postoperative ${ }^{31}$. These results accord with the findings of Takeuchi et al ${ }^{32}$, Jeon et al. ${ }^{33}$, Ryu et al. ${ }^{34}$.

UKA is associated with less perioperative blood loss, quicker recovery, and no immobilisation. A report by Jeon et al. showed a better postoperative activity level following UKA compared to HTO at 6 months, whereas at 12 months and 2-year follow-up no significant differences were reported in the compared groups ${ }^{33}$. A study by Borjesson et al. reported an increased free walking speed from 1.07 to 1.16 $\mathrm{m} / \mathrm{s}$ in the UKA group compared to the HTO group which was associated with decreased free walking speed from 1.07 to $0.94 \mathrm{~m} / \mathrm{s}$ three months postoperatively. However, comparable results were observed between the two groups at the follow-up durations of 1 and 5 years 35 . Based on the previous reasons, UKA offers improved postoperative functional outcomes than HTO in short-term follow-up while no difference was found in long-term results.

\section{Strengths and limitations}

The current meta-analysis included some new studies up to $2021^{30,31,36-39}$; thus, our results are more up to date. We determined search methods and performed a comprehensive search using many electronic databases and we followed the PRISMA checklist when reporting this manuscript. However, a limitation of our meta-analysis is the heterogeneity in some of the included outcomes. The heterogeneity might be due to the included different study designs, matching criteria, sample size, operative techniques, and measurement of outcomes. These variances may lead to significant between-study heterogeneity, which can impact the results in the current study. We used the random effects model to decrease the impact of heterogeneity; however, it does not eliminate it.

\section{Conclusion}

This meta-analysis of 25 studies showed that UKA achieved less rate of complications, better functional outcomes (excellent/good), and less range of motion compared to HTO. No significant differences were detected between HTO and UKA in terms of visual analogue scale, revision rate, and free walking speed.

\section{Abbreviations}


$\mathrm{Cl}$

Confidence interval

CW

Closing wedge

CWHTO

Close-wedge high tibial osteotomy

HTO

High tibial osteotomy

MD

Mean difference

NOS

Newcastle Ottawa scale

OR

Odds ration

OW

Opening wedge

OWHTO

Open-wedge high tibial osteotomy

PCA

Porous coated anatomic implant.

PRISMA

Preferred Reporting Items for Systematic Reviews and Meta-Analysis

PROSPERO

International Prospective Register of Systematic Reviews

RCT

Randomized clinical trial

SD

Standard deviation

UKA

Unicompartmental knee arthroplasty

VAS

Visual analogue scale

\section{Declarations}

Acknowledgement: None to declare

\section{Funding}

Not applicable

\section{Conflicts of interest/Competing interests}

Ishith Seth declares that he has no conflict of interest.

Nimish Seth declares that he has no conflict of interest.

Gabriella Bulloch declares that she has no conflict of interest.

Damien Gibson declares that he has no conflict of interest.

Kirk Lower declares that he has no conflict of interest.

Aaron Rodwell declares that he has no conflict of interest.

Warwick Bruce declares that he has no conflict of interest. 
Availability of data and material

The raw extracted data are available upon requested

\section{Code availability}

Not applicable

\section{Authors' contributions}

IS: Methodology, Investigation, Project administration, Formal data analysis, Writing - original draft, Writing - review and editing.

NS: Methodology, Investigation, Project administration, Formal data analysis, Writing - original draft, Writing - review and editing.

GB: Methodology, Investigation, Writing - review and editing.

DG: Methodology, Investigation, Writing - review and editing.

$\mathrm{KL}$ : Methodology, Investigation, Writing - review and editing.

AR: Methodology, Writing - review and editing.

WB: Conceptualization, Methodology, Supervision, Writing - review and editing.

\section{Ethics approval}

Not applicable

\section{Consent to participate}

The authors confirm their participation in the current manuscript.

\section{Consent for publication}

The authors consent to publish the current manuscript.

\section{References}

1. March LM, Schwarz JM, Carfrae BH, Bagge E. Clinical validation of self-reported osteoarthritis Osteoarthritis and Cartilage 1998;6(2):8793.

2. Tetsworth K, Paley D. Malalignment and degenerative arthropathy Orthopedic Clinics of North America 1994;25(3):367-77.

3. McAlindon TE, Bannuru RR, Sullivan MC, Arden NK, Berenbaum F, Bierma-Zeinstra SM, et al. OARSI guidelines for the non-surgical management of knee osteoarthritis Osteoarthritis and Cartilage 2014;22(3):363-88.

4. Akizuki S, Shibakawa A, Takizawa T, Yamazaki I, Horiuchi H. The long-term outcome of high tibial osteotomy: A ten- to 20-year followup Journal of Bone and Joint Surgery - Series B 2008;90(5):592-96.

5. Amendola A. Unicompartmental Osteoarthritis in the Active Patient: The Role of High Tibial Osteotomy In: Arthroscopy - Journal of Arthroscopic and Related Surgery Vol 19 W.B. Saunders; 2003. pp. 109-16.

6. Rossi R, Bonasia DE, Amendola A. The role of high tibial osteotomy in the varus knee Journal of the American Academy of Orthopaedic Surgeons 2011;19(10):590-99.

7. Amendola A, Panarella L. High tibial osteotomy for the treatment of unicompartmental arthritis of the knee Orthopedic Clinics of North America 2005;36(4):497-504.

8. Danford N, Grosso M, Heller MS, Murtaugh T, Shah RP, Cooper HJ, et al. Which do patients prefer, unicompartmental or total knee arthroplasty? Journal of Clinical Orthopaedics and Trauma 2018;9(4):292-94.

9. Borus T, Thornhill T. Unicompartmental knee arthroplasty Journal of the American Academy of Orthopaedic Surgeons 2008;16(1):9-18.

10. Dettoni F, Bonasia DE, Castoldi F, Bruzzone M, Blonna D, Rossi R. High tibial osteotomy versus unicompartmental knee arthroplasty for medial compartment arthrosis of the knee: a review of the literature. The lowa orthopaedic journal 2010;30:131-40. 
11. Santoso MB, Wu L. Unicompartmental knee arthroplasty, is it superior to high tibial osteotomy in treating unicompartmental osteoarthritis? A meta-analysis and systemic review Journal of Orthopaedic Surgery and Research 2017;12(1).

12. Higgins JPT, Green S. Cochrane Handbook for Systematic Reviews of Interventions Vol 4. John Wiley \& Sons; 2011

13. Altman DG. Standard deviations and standard errors BMJ 2005;331(7521):903-903.

14. Stang A. Critical evaluation of the Newcastle-Ottawa scale for the assessment of the quality of nonrandomized studies in metaanalyses. European journal of epidemiology 2010;25(9):603-5.

15. Kozinn S, JBJS RS-, 1989 undefined. Unicondylar knee arthroplasty. journals.lww.com .

16. Tabor OB, Tabor OB, Bernard M, Wan JY. Unicompartmental knee arthroplasty: long-term success in middle-age and obese patients. Journal of surgical orthopaedic advances 2005;14(2):59-63.

17. Plate JF, Augart MA, Seyler TM, Bracey DN, Hoggard A, Akbar M, et al. Obesity has no effect on outcomes following unicompartmental knee arthroplasty Knee Surgery, Sports Traumatology, Arthroscopy 2017;25(3):645-51.

18. Pennington DW, Swienckowski JJ, Lutes WB, Drake GN. Unicompartmental knee arthroplasty in patients sixty years of age or younger Journal of Bone and Joint Surgery - Series A 2003;85(10):1968-73.

19. Felts E, Parratte S, Pauly V, Aubaniac JM, Argenson JN. Function and quality of life following medial unicompartmental knee arthroplasty in patients 60years of age or younger Orthopaedics and Traumatology: Surgery and Research 2010;96(8):861-67.

20. Lee DC, Byun SJ. High Tibial Osteotomy Knee Surgery \& Related Research 2012;24(2):61-69.

21. Zuiderbaan HA, Van Der List JP, Kleeblad LJ, Appelboom P, Kort NP, Pearle AD, et al. Modern Indications, Results, and Global Trends in the Use of Unicompartmental Knee Arthroplasty and High Tibial Osteotomy in the Treatment of Isolated Medial Compartment Osteoarthritis

22. Trieb K, Grohs J, Hanslik-Schnabel B, Stulnig T, Panotopoulos J, Wanivenhaus A. Age predicts outcome of high-tibial osteotomy Knee Surgery, Sports Traumatology, Arthroscopy 2006;14(2):149-52.

23. Smith WB, Steinberg J, Scholtes S, Mcnamara IR. Medial compartment knee osteoarthritis: age-stratified cost-effectiveness of total knee arthroplasty, unicompartmental knee arthroplasty, and high tibial osteotomy Knee Surgery, Sports Traumatology, Arthroscopy 2017;25(3):924-33.

24. Nwachukwu BU, McCormick FM, Schairer WW, Frank RM, Provencher MT, Roche MW. Unicompartmental Knee Arthroplasty Versus High Tibial Osteotomy: United States Practice Patterns for the Surgical Treatment of Unicompartmental Arthritis Journal of Arthroplasty 2014;29(8):1586-89.

25. Sun H, Zhou L, Li F, Duan J. Comparison between Closing-Wedge and Opening-Wedge High Tibial Osteotomy in Patients with Medial Knee Osteoarthritis: A Systematic Review and Meta-analysis Journal of Knee Surgery 2017;30(2):158-65.

26. Spahn G, Hofmann GO, von Engelhardt LV, Li M, Neubauer H, Klinger HM. The impact of a high tibial valgus osteotomy and unicondylar medial arthroplasty on the treatment for knee osteoarthritis: A meta-analysis Knee Surgery, Sports Traumatology, Arthroscopy 2013;21(1):96-112.

27. Cao ZW, Mai XJ, wang J, Feng EH, Huang YM. Uni-compartmental knee arthroplasty versus high tibial osteotomy for knee osteoarthritis: a systematic review and meta-analysis Journal of Arthroplasty 2018;33(3):952-59.

28. Dean CS, Liechti DJ, Chahla J, Moatshe G, LaPrade RF. Clinical Outcomes of High Tibial Osteotomy for Knee Instability: A Systematic Review Orthopaedic Journal of Sports Medicine 2016;4(3).

29. Koshino T, Saito T, Orito K, Mitsuhashi S, Takeuchi R, Kurosaka T. Increase in range of knee motion to obtain floor sitting after high tibial osteotomy for osteoarthritis Knee 2002;9(3):189-96.

30. Koh IJ, Kim MS, Sohn S, Song KY, Choi NY, Jung H, et al. Predictive factors for satisfaction after contemporary unicompartmental knee arthroplasty and high tibial osteotomy in isolated medial femorotibial osteoarthritis Orthopaedics and Traumatology: Surgery and Research 2019;105(1):77-83.

31. Kim MS, Koh IJ, Sohn S, Jeong JH, In Y. Unicompartmental knee arthroplasty is superior to high tibial osteotomy in post-operative recovery and participation in recreational and sports activities International Orthopaedics 2019;43(11):2493-2501.

32. Takeuchi R, Umemoto Y, Aratake M, Bito H, Saito I, Kumagai K, et al. A mid term comparison of open wedge high tibial osteotomy vs unicompartmental knee arthroplasty for medial compartment osteoarthritis of the knee Journal of Orthopaedic Surgery and Research 2010;5(1):1-8.

33. Jeon YS, Ahn CH, Kim MK. Comparison of HTO with articular cartilage surgery and UKA in unicompartmental OA Journal of Orthopaedic Surgery 2017;25(1):1-6. 
34. Ryu SM, Park JW, Na HD, Shon OJ. High Tibial Osteotomy versus Unicompartmental Knee Arthroplasty for Medial Compartment Arthrosis with Kissing Lesions in Relatively Young Patients Knee Surgery and Related Research 2018;30(1):17-22.

35. Börjesson M, Weidenhielm L, Mattsson E, Olsson E. Gait and clinical measurements in patients with knee osteoarthritis after surgery: A prospective 5-year follow-up study Knee 2005;12(2):121-27.

36. Bouguennec N, Mergenthaler G, Gicquel T, Briand C, Nadau E, Pailhé R, et al. Medium-term survival and clinical and radiological results in high tibial osteotomy: Factors for failure and comparison with unicompartmental arthroplasty Orthopaedics and Traumatology: Surgery and Research 2020;106(8):S223-30.

37. Jacquet C, Gulagaci F, Schmidt A, Pendse A, Parratte S, Argenson JN, et al. Opening wedge high tibial osteotomy allows better outcomes than unicompartmental knee arthroplasty in patients expecting to return to impact sports Knee Surgery, Sports Traumatology, Arthroscopy 2020;28(12):3849-57.

38. Jin QH, Lee WG, Song EK, Jin C, Seon JK. Comparison of Long-Term Survival Analysis Between Open-Wedge High Tibial Osteotomy and Unicompartmental Knee Arthroplasty Journal of Arthroplasty 2020:1-7.

39. Ziqi Z, Yufeng M, Lei Z, Chunsheng W, Pei Y, Kunzheng W. Therapeutic Effects Comparison and Revision Case Analysis of Unicompartmental Knee Arthroplasty and Open Wedge High Tibial Osteotomy in Treating Medial Knee Osteoarthritis in Patients Under 60 years: A 2-6-year Follow-up Study Orthopaedic Surgery 2020;12(6):1635-43.

40. Krych AJ, Reardon P, Sousa P, Pareek A, Stuart M, Pagnano M. Unicompartmental knee arthroplasty provides higher activity and durability than valgus-producing proximal tibial osteotomy at 5 to 7 years Journal of Bone and Joint Surgery - American Volume 2017;99(2):113-22.

41. Petersen W, Metzlaff S. Open wedge high tibial osteotomy (HTO) versus mobile bearing unicondylar medial joint replacement: five years results Archives of Orthopaedic and Trauma Surgery 2016;136(7):983-89.

42. Stukenborg-Colsman C, Wirth CJ, Lazovic D, Wefer A. High tibial osteotomy versus unicompartmental joint replacement in unicompartmental knee joint osteoarthritis: 7-10-Year follow-up prospective randomised study Knee 2001;8(3):187-94.

43. Yim JH, Song EK, Seo HY, Kim MS, Seon JK. Comparison of High Tibial Osteotomy and Unicompartmental Knee Arthroplasty at a Minimum Follow-Up of 3 Years Journal of Arthroplasty 2013;28(2):243-47.

44. Weidenhielm L, Svensson OK, Broström LÅ, Rudberg U. Change in adduction moment about the knee after high tibial osteotomy and prosthetic replacement in osteoarthrosis of the knee Clinical Biomechanics 1992;7(2):91-96.

45. Weidenhielm L, Olsson E, ... LB-S journal, 1993 undefined. Improvement in gait one year after surgery for knee osteoarthrosis: a comparison between high tibial osteotomy and prosthetic replacement in a prospective europepmc.org .

46. Ivarsson I, research JG-C orthopaedics and related, 1991 undefined. Rehabilitation after high tibial osteotomy and unicompartmental arthroplasty. A comparative study. europepmc.org .

47. Tuncay I, Bilsel K, Elmadağ M, Erkoçak ÖF, Aşçi M, Şen C. Evaluation of mobile bearing unicompartmental knee arthroplasty, opening wedge, and dome-type high tibial osteotomies for knee arthritis Acta Orthopaedica et Traumatologica Turcica 2015;49(3):280-87.

48. Karamitev SS, Stavrev VP, Chifligarov AG. Comparative analysis of the results obtained after unicondylar knee arthroplasty and high tibial osteotomy in isolated gonarthrosis. Folia medica 2014;56(1):11-19.

49. W-Dahl A, Robertsson O, Lidgren L. Surgery for knee osteoarthritis in younger patients: A Swedish register study Acta Orthopaedica 2010;81(2):161-64.

50. Weale A, related JN-C orthopaedics and, 1994 undefined. Unicompartmental arthroplasty and high tibial osteotomy for osteoarthrosis of the knee. A comparative study with a 12-to 17-year follow-up period. europepmc.org .

51. Jefferson RJ, Whittle MW. Biomechanical assessment of unicompartmental knee arthroplasty, total condylar arthroplasty and tibial osteotom Clinical Biomechanics 1989;4(4):232-42.

52. Broughton NS, Newman JH, Baily RAJ. Unicompartmental replacement and high tibial osteotomy for osteoarthritis of the knee. A comparative study after 5-10 years' follow-up Journal of Bone and Joint Surgery - Series B 1986;68(3):447-52.

53. Karpman RR, Volz RG. Osteotomy versus unicompartmental prosthetic replacement in the treatment of unicompartmental arthritis of the knee Orthopedics 1982;5(8):989-91.

\section{Tables}


Table 1

Summary of included studies.

\begin{tabular}{|c|c|c|c|c|c|c|c|c|c|c|}
\hline \multirow[t]{2}{*}{ Author, year } & \multirow[t]{2}{*}{ Study design } & \multirow{2}{*}{$\begin{array}{l}\text { Follow } \\
\text { up } \\
\text { (months) }\end{array}$} & \multicolumn{2}{|c|}{$\begin{array}{l}\text { Number of } \\
\text { patients }\end{array}$} & \multicolumn{2}{|c|}{ Female (n) } & \multicolumn{2}{|c|}{ Mean age } & \multicolumn{2}{|l|}{ Type of implant } \\
\hline & & & HTO & UKA & HTO & UKA & HTO & UKA & HTO & UKA \\
\hline \multicolumn{11}{|l|}{ RCTs } \\
\hline $\begin{array}{l}\text { Ryu et al., } \\
2018^{34}\end{array}$ & RCT & 36.55 & 23 & 22 & 21 & 19 & 57.6 & 60.5 & $\begin{array}{l}\text { Chronos vivify } \\
\text { spacer + } \\
\text { TomoFix } \\
\text { (DePuy } \\
\text { Synthes) }\end{array}$ & $\begin{array}{l}\text { Sigma } \\
\text { (DePuy) }\end{array}$ \\
\hline $\begin{array}{l}\text { Jeon et al., } \\
201733\end{array}$ & $\mathrm{RCT}$ & 24 & 26 & 21 & 22 & 17 & 56.8 & 60.7 & $\begin{array}{l}\text { TomoFix } \\
\text { (DePuy } \\
\text { Synthes) }\end{array}$ & High Flex (Zimmer) \\
\hline $\begin{array}{l}\text { Krych et al., } \\
201740\end{array}$ & $\mathrm{RCT}$ & 84 & 57 & 183 & 16 & 101 & 48 & 47 & NR & $\begin{array}{l}\text { Miller-Galante } \\
\text { (Zimmer) }\end{array}$ \\
\hline $\begin{array}{l}\text { Petersen et } \\
\text { al., } 2016^{41}\end{array}$ & $\mathrm{RCT}$ & 60 & 23 & 25 & 9 & 16 & 58.9 & 60.7 & $\begin{array}{l}\text { Miller-Galante } \\
\text { (Zimmer) }\end{array}$ & $\begin{array}{l}\text { TomoFix (DePuy } \\
\text { Synthes) }\end{array}$ \\
\hline $\begin{array}{l}\text { Borjesson et } \\
\text { al., } 2005^{35}\end{array}$ & RCT & 60 & 18 & 22 & 10 & 11 & 63 & 63 & CW-HTO & Bragham \\
\hline $\begin{array}{l}\text { Stukenborg- } \\
\text { Colsman et } \\
\text { al., } 2001^{42}\end{array}$ & RCT & 90 & 32 & 28 & 13 & 22 & 67 & 67 & $\begin{array}{l}\text { Five-hole-two- } \\
\text { thirds tubular } \\
\text { plate and a } \\
\text { cortical screw }\end{array}$ & $\begin{array}{l}\text { Unicondylar knee } \\
\text { sliding } \\
\text { (Aesculap) }\end{array}$ \\
\hline $\begin{array}{l}\text { Takeuchi et } \\
\text { al., } 2010^{32}\end{array}$ & $\mathrm{RCT}$ & 72.5 & 24 & 18 & 18 & 14 & 67 & 77 & $\begin{array}{l}\text { TomoFix } \\
\text { (DePuy } \\
\text { Synthes) }\end{array}$ & $\begin{array}{l}\text { Uni-Knee (Nakashima } \\
\text { Propeller Co) }\end{array}$ \\
\hline $\begin{array}{l}\text { Yim et al., } \\
2013^{43}\end{array}$ & RCT & 43.8 & 58 & 50 & 51 & 48 & 58.3 & 60.3 & $\begin{array}{l}2 \text { wedge plates } \\
\text { (Aesculap) }\end{array}$ & $\begin{array}{l}\text { Miller-Galante } \\
\text { (Zimmer) }\end{array}$ \\
\hline $\begin{array}{l}\text { Weidenhielm } \\
\text { et al., } 1992 \\
44\end{array}$ & RCT & 12 & 25 & 28 & 28 & & 63 & 63 & Coventry & Brigham \\
\hline $\begin{array}{l}\text { Weidenhielm } \\
\text { et al., } 1993 \\
45\end{array}$ & RCT & 12 & 23 & 36 & 13 & 18 & NR & NR & NR & NR \\
\hline $\begin{array}{l}\text { Ivarsson et } \\
\text { al., } 1991^{46}\end{array}$ & RCT & 12 & 10 & 10 & 6 & 6 & 62 & 64 & CWHTO & Oxford/PCA \\
\hline \multicolumn{11}{|c|}{ Observational studies } \\
\hline $\begin{array}{l}\text { Bouguennec } \\
\text { et al., } 2020 \\
36\end{array}$ & Retrospective & 93.6 & 488 & 284 & 153 & 172 & 55.1 & 64.1 & $\begin{array}{l}\text { Bylocking plate, } \\
\text { non-locking } \\
\text { plate, blade- } \\
\text { plate or staples }\end{array}$ & cementedpolyethylene, \\
\hline $\begin{array}{l}\text { Jacquet et } \\
\text { al., } 2020^{37}\end{array}$ & Retrospective & 46.8 & 50 & 50 & 22 & 21 & 49.3 & 50.8 & $\begin{array}{l}\text { Locking screw } \\
\text { plate }\end{array}$ & $\begin{array}{l}\text { ZUK LIMACorporate } \\
\text { Undine }\end{array}$ \\
\hline $\begin{array}{l}\text { Jin et al., } \\
2020^{38}\end{array}$ & Retrospective & 120 & 67 & 67 & 247 & 65 & 53.9 & 63.1 & $\begin{array}{l}\text { Aescula, } \\
\text { Aesculap, } \\
\text { Korea; Medyfix, } \\
\text { Medyssey, } \\
\text { Korea }\end{array}$ & $\begin{array}{l}\text { Miller-Galante } \\
\text { (Zimmer) }\end{array}$ \\
\hline $\begin{array}{l}\text { Ziqi et al., } \\
2020^{39}\end{array}$ & Retrospective & 40.2 & 109 & 83 & 86 & 66 & 51.8 & 53.7 & OWHTO & NR \\
\hline
\end{tabular}

RCT: randomized clinical trials, HTO: high tibial osteotomy, UKA: unicompartmental knee arthroplasty, CWHTO: close-wedge high tibial osteotomy, OWHTO: open-wedge high tibial osteotomy, PCA porous coated anatomic implant. 


\begin{tabular}{|c|c|c|c|c|c|c|c|c|c|c|}
\hline \multirow[t]{2}{*}{ Author, year } & \multirow[t]{2}{*}{ Study design } & \multirow{2}{*}{$\begin{array}{l}\text { Follow } \\
\text { up } \\
\text { (months) }\end{array}$} & \multicolumn{2}{|c|}{$\begin{array}{l}\text { Number of } \\
\text { patients }\end{array}$} & \multicolumn{2}{|c|}{ Female (n) } & \multicolumn{2}{|c|}{ Mean age } & \multicolumn{2}{|l|}{ Type of implant } \\
\hline & & & нтO & UKA & Нто & UKA & HTO & UKA & нто & UKA \\
\hline $\begin{array}{l}\text { Kim et al., } \\
2019^{31}\end{array}$ & Prospective & 24 & 49 & 42 & 43 & 35 & 56.1 & 63.6 & $\begin{array}{l}\text { TomoFix® } \\
\text { (DePuySynthes) }\end{array}$ & Oxford III (Zimmer) \\
\hline $\begin{array}{l}\text { Koh et al., } \\
2018^{30}\end{array}$ & Retrospective & 36 & 123 & 118 & 104 & 98 & 56.1 & 60.8 & $\begin{array}{l}\text { TomoFix } \\
\text { (DePuySynthes) }\end{array}$ & Oxford III (Zimmer) \\
\hline $\begin{array}{l}\text { Tuncay et } \\
\text { al., } 2015^{47}\end{array}$ & Retrospective & 42 & 88 & 94 & 28 & 79 & 53.5 & 58.7 & $\begin{array}{l}\text { DT-HTO, OW- } \\
\text { HTO }\end{array}$ & Oxford III \\
\hline $\begin{array}{l}\text { Karamitev et } \\
\text { al., } 2014{ }^{48}\end{array}$ & Retrospective & 48 & 92 & 65 & 45 & 42 & NR & $\begin{array}{l}52- \\
84\end{array}$ & LCW-HTO & NR \\
\hline $\begin{array}{l}\text { W-Dahl et } \\
\text { al., } 2010^{49}\end{array}$ & $\begin{array}{l}\text { Register } \\
\text { study }\end{array}$ & NR & 450 & 4799 & NR & NR & $\begin{array}{l}30- \\
64\end{array}$ & $\begin{array}{l}30- \\
64\end{array}$ & Hemicallotasis & NR \\
\hline $\begin{array}{l}\text { Dettoni et } \\
\text { al., } 2008{ }^{10}\end{array}$ & Prospective & 48 & 54 & 56 & NR & NR & NR & NR & OWHTO & Accuris \\
\hline $\begin{array}{l}\text { Weale et al., } \\
1994^{50}\end{array}$ & Retrospective & 204 & 21 & 15 & NR & NR & 74 & 80 & CWHTO & St Georg \\
\hline $\begin{array}{l}\text { Jefferson RJ } \\
\text { et al., } 1989 \\
51\end{array}$ & Prospective & NR & 20 & 20 & NR & NR & 57 & 65 & CWHTO & Oxford \\
\hline $\begin{array}{l}\text { Broughton et } \\
\text { al., } 1986^{52}\end{array}$ & Retrospective & 793.6 & 45 & 34 & 38 & 31 & 71 & 63 & CWHTO & St Georg \\
\hline $\begin{array}{l}\text { Karpman et } \\
\text { al., } 198253\end{array}$ & Retrospective & 24 & 21 & 19 & 3 & 4 & 57 & 62 & CWHTO & NR \\
\hline
\end{tabular}

\section{Figures}




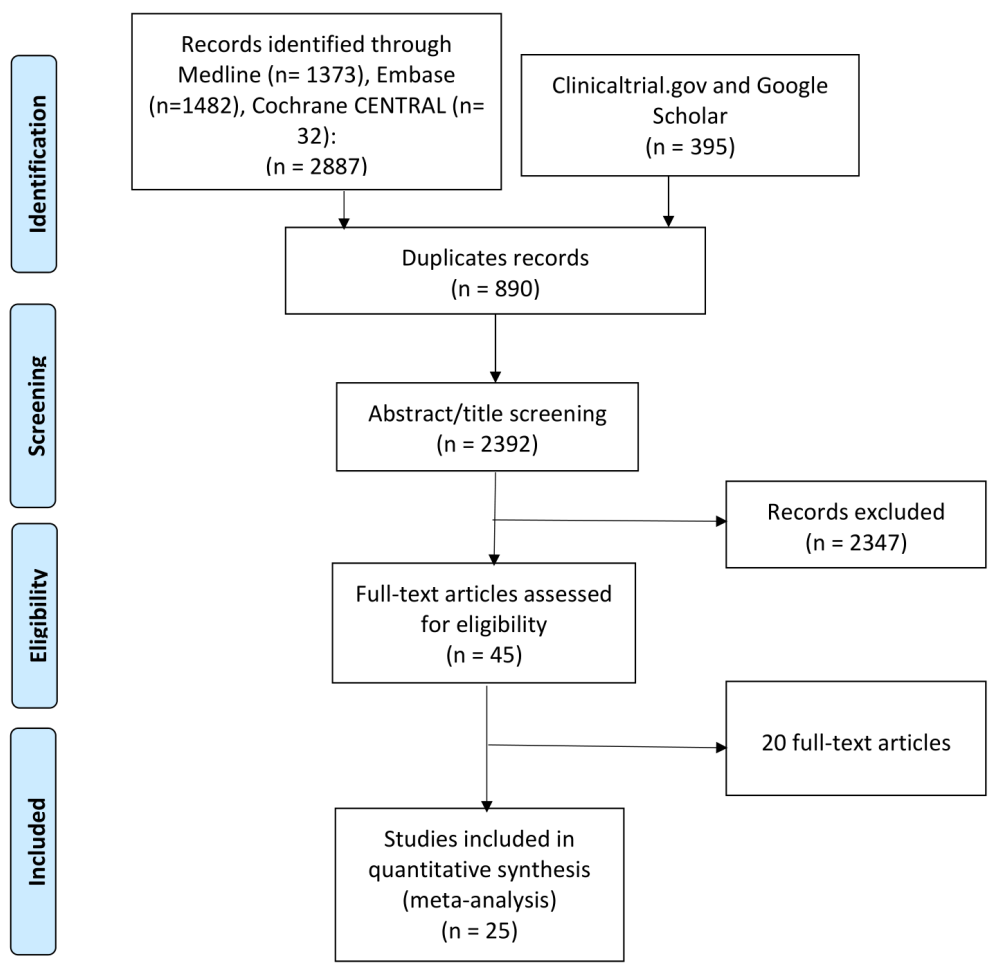

Figure 1

PRISMA flow diagram of study selection. 


\section{Study}

Stukenborg-Colsman et al 2001 Broughton et al 1986 Weale AE et al 1994 Tuncay et al 2015 Petersen et al 2016 Dettoni et al 2008 Jeon et al 2017 Ryu et al 2018 Yim et al 2013 Takeuchi et al 2010 Ziqi et al 2020

Fixed effect model Heterogeneity: $I^{2}=0 \%, p=0.52$
Odds Ratio

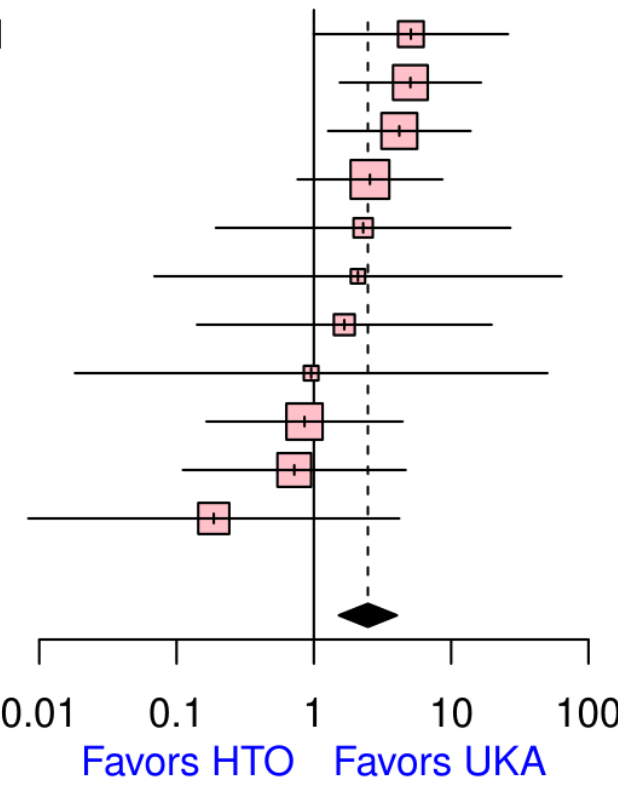

OR $\quad 95 \%-C l$ Weight

$5.09[1.00 ; 26.01] \quad 7.1 \%$ $5.05[1.54 ; 16.53] \quad 13.0 \%$ $4.19[1.27 ; 13.86] \quad 13.8 \%$ $2.56[0.76 ; 8.65] 16.1 \%$ $2.29[0.19 ; 27.05] \quad 4.0 \%$ $2.09[0.07 ; 63.74] \quad 2.2 \%$ $1.67[0.14 ; 19.76] \quad 4.7 \%$ $0.96[0.02 ; 50.34] \quad 2.3 \%$ $0.85[0.16 ; 4.44] 14.1 \%$ $0.72[0.11 ; 4.67] 12.2 \%$ $0.19[0.01 ; 4.19] \quad 10.4 \%$ $2.47[1.52 ; 4.04] 100.0 \%$

\section{Figure 2}

Forest plot of complications comparing HTO vs UKA. 


\section{Study}

Takeuchi et al 2010

Stukenborg-Colsman et al 2001

Dettoni et al 2008

Weale AE et al 1994

Broughton et al 1986

Ivarsson et al 1991

Petersen et al 2016

Karamitev et al 2014

Karpman et al 1982

Borjesson et al 2005

\section{Fixed effect model}

Heterogeneity: $I^{2}=45 \%, p=0.07$
Odds Ratio

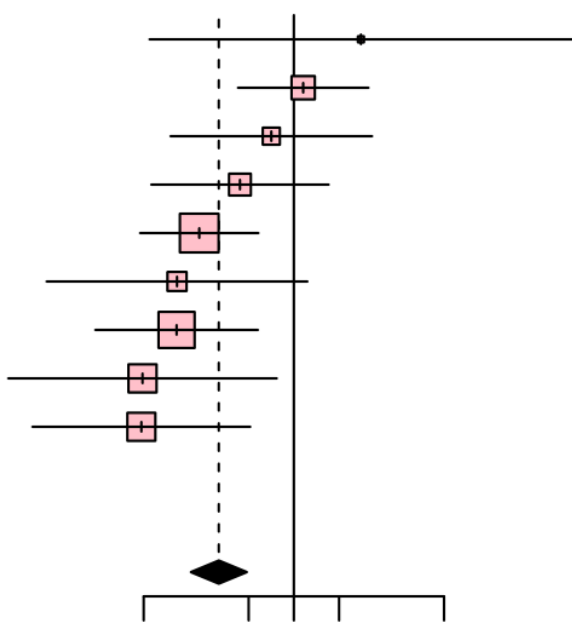

$\begin{array}{llll}0.1 & 0.512 & 10\end{array}$

Favors UKA Favors HTO
OR $\quad 95 \%-\mathrm{Cl}$ Weight

$2.80[0.11 ; 71.59] \quad 0.6 \%$

$1.15[0.42 ; 3.14] \quad 8.9 \%$

$0.71 \quad[0.15 ; 3.32] \quad 4.8 \%$

$0.44[0.11 ; 1.71] \quad 7.8 \%$

$0.23[0.09 ; 0.58] 24.6 \%$

$0.17[0.02 ; 1.23] \quad 6.0 \%$

0.17 [0.05; 0.58$] 21.4 \%$

$0.10[0.01 ; 0.77] 13.0 \%$

0.10 [0.02;0.51] $12.9 \%$

$0.0 \%$

$0.32[0.21 ; 0.49] 100.0 \%$

\section{Figure 3}

Forest plot of functional outcomes (excellent/good results) comparing HTO vs UKA. 


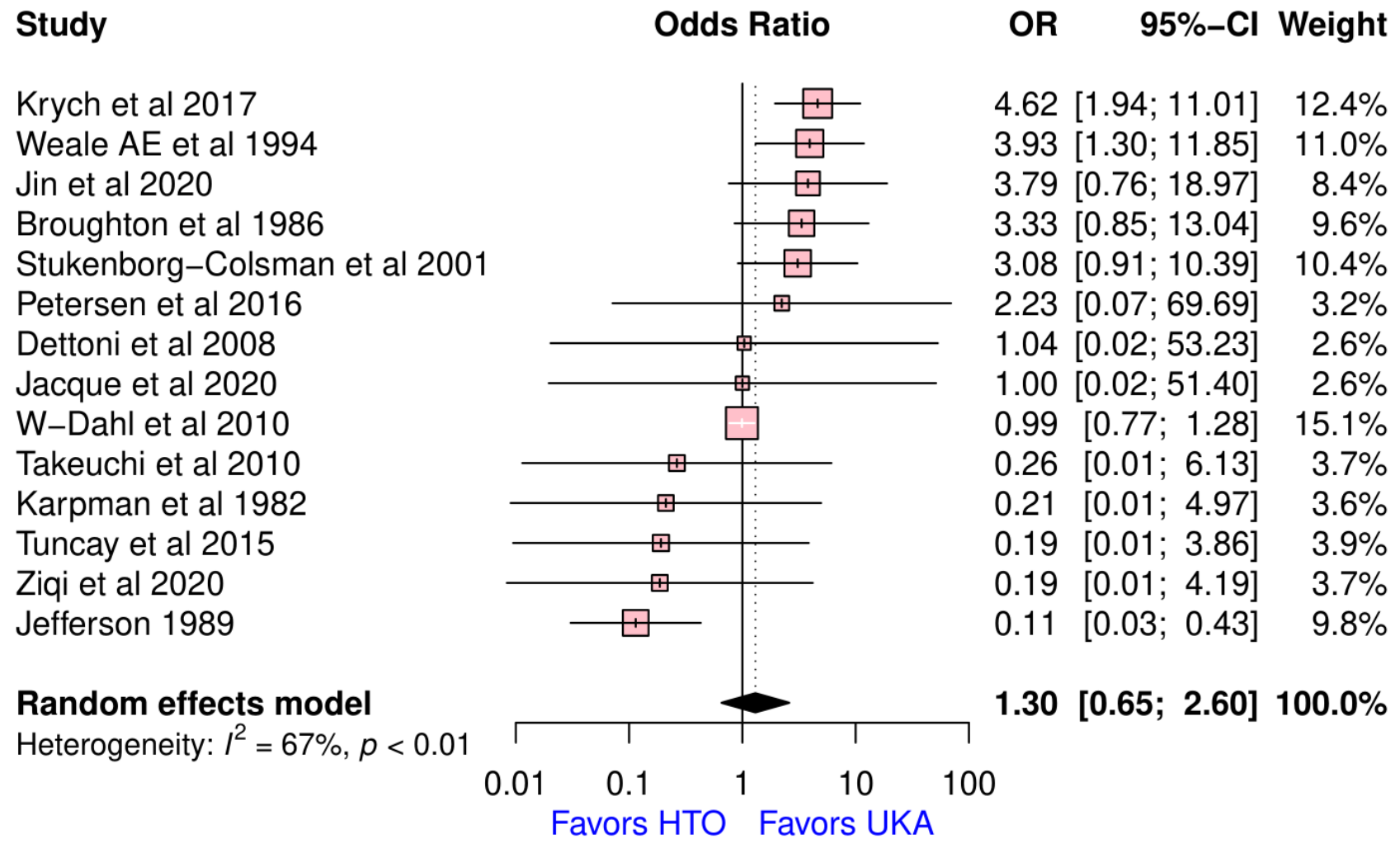

Figure 4

Forest plot of survival and revision comparing HTO vs UKA.

\section{Supplementary Files}

This is a list of supplementary files associated with this preprint. Click to download.

- Appendixfile.docx 